\title{
ANALISIS TREN DAN PERBANDINGAN RASIO ISLAMICITY PERFORMANCE PADA BANK SYARIAH MANDIRI, BANK MUAMALAT INDONESIA, BANK BRI SYARIAH DAN BANK BNI SYARIAH PERIODE 2011-20141]
}

\author{
Harvita Ayu Lutfiandari \\ Program Studi Ekonomi Islam-Fakultas Ekonomi dan Bisnis-Universitas Airlangga \\ Email: harvita.ayu@gmail.com \\ Dina Fitrisia Septiarini \\ Departemen Ekonomi Syariah-Fakultas Ekonomi dan Bisnis-Universitas Airlangga \\ Email: dina.fitrisia@gmail.com
}

\begin{abstract}
:
This study is aimed to investigate the trend of financial performances and the difference of Islamicity Performance Ratioamong Islamic banks in Indonesia during 2011-2014. The quantitative approach of purposive sampling is used as the research method. The data collected frombank's annual financial statements (2011-2014) used as sample: Bank Syariah Mandiri, Bank Muamalat Indonesia, Bank BNI Syariah and BRI Syariah. The data collected then analyzed using the trend analysis and ANOVA. Six variables: PSR, ZPR, EDR, DEWR, IIR and ISIR, are used as proxies for Islamicity Performance Ratio.

Trend analysis shows that BRI Syariah has better PSR, ZPR, EDR, ISIR compared to other banks except for DEWR. IIR of Bank Muamalat is the best among others. Comparative analysis shows there are differences of Islamicity Performance Ratioamong Islamic banks in terms of PSR, EDR and DEWR, nevertheless there is no difference in terms of ZPR, IIR and ISIR.
\end{abstract}

Keywords : Trend Analysis, Analysis of Comparative, Islamicity Performance, Islamic Banks

\section{Pendahuluan}

Pertumbuhan perbankan syariah nasional relatif cepat. Berawal dari berdirinya Bank Muamalat tahun 1992 kemudian disetujuinya UU No.10 tahun 1998 yang diatur sebagai landasan hukum yang terus menggiring gerakan perkembangan ekonomi syariah di Indonesia. Dibentuknya UU RI No.21 tahun 2008 tentang perbankan syariah yang menjadi payung hukum operasional merubah bank syariah menjadi lebih terarah dan terlindungi oleh hukum negara.

Konsep kerja perbankan syariah dalam menjalankan kegiatannya menggunakan sistem bagi hasil. Berbeda

pada bank konvensional melaksanakan kegiatan usahanya dengan menggunakan sistem bunga (riba) (Muhammad, 2014:5). Allah SWT yang melarang praktik riba (bunga) dalam Surat Al-Baqarah ayat 278-279:

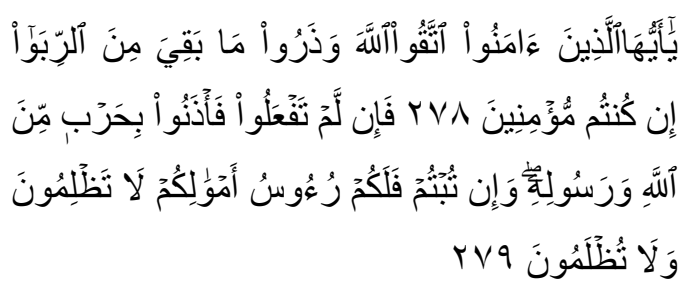

YÉayyuhallażêEnaÉmanËttaqullÉha ważarËmÉbaqiya minar-ribÉing kuntum mu'minÊn. $F a$ il lam taf'alëfa'żanËbiĺarbim minallÉhi wa rasëlih, wa in tubtum fa lakum ru'Ësu amwÉlikum, IÉtaĐlimËna walÉ tUĐlamën

\footnotetext{
1.Jurnal ini merupakan bagian dari skripsi dari Harvita Ayu Lutfiandari, NIM. 04121 1433089, yang diuji pada tanggal 12 Februari 2016.
} 
Lutfiandari, et al/Jurnal Ekonomi Syariah Teori dan Terapan Vol. 3 No. 6 Juni 2016: 430-443; ANALISIS TREN DAN PERBANDINGAN RASIO ISLAMICITY PERFORMANCE PADA BANK SYARIAH MANDIRI, BANK MUAMALAT INDONESIA, BANK BRI SYARIAH DAN BANK BNI SYARIAH PERIODE 2011-2014

"Hai orang-orang yang beriman, bertakwalah kepada Allah dan tinggalkan sisa riba (yang belum dipungut)jika kamu orang-orang yang beriman. Maka jika kamu tidak menegrjakan (meningglakan sisa riba), maka ketahuilah, bahwa Allah dan Rasul-Nya akan memerangimu. Dan jika kamu bertaubat (dari pengambilan riba), maka bagimu pokok hartamu; kamu tidak menganiaya dan tidak (pula) dianiaya." (Departemen Agama Rl, Mushaf Al-Quran dan Terjemahannya Revisi tahun 2004).

Sebagai Lembaga Keuangan

Islam yang sedang tumbuh dan berkembang, bank syariah membutuhkan sebuah kontrol atau evaluasi agar semakin berkembang dan mencapai tujuan. Menurut Hameed et al (2004) mengukur kinerja lembaga keuangan Islam saat ini dipandang penting karena ada tumbuh kesadaran dari masyarakat muslim untuk menilai sejauh mana lembaga-lembaga keuangan Islam khususnya perbankan syariah telah mencapai tujuannya.

Terdapat berbagai cara untuk mengukur kinerja keuangan perbankan. Bank Indonesia telah menetapkan ketentuan tingkat kesehatan bank melalui Surat Edaran Bank Indonesia No.26/BPPP/1993 tanggal 18 Mei 1993 yang dikenal dengan metode CAMEL. Namun untuk pengukuran kinerja bank syariah, metode CAMEL tidak cukup representatif. Hal ini disebabkan, pengukuran dengan metode CAMEL hanya dapat menunjukkan kinerja bisnisnya. Sementara dalam bank syariah tidak hanya terfokus pada tujuan komersil tetapi juga mempertimbangkan perannya selaku pelaksana fungsi sosial.

Hameed et al (2004) telah mengembangkan pengukuran baru untuk instistusi Islam yang disebut Islamicity Performance Index sehingga kinerja dari institusi Islam dapat dievaluasi seluruhnya. Islamicity Performance Index merupakan salah satu alat pengukuran kinerja yang dapat menunjukkan seberapa besar tingkat kinerja berdasarkan aktivitasnya yang sesuai dengan prinsip syariah. Dalam penelitian ini menggunakan enam rasio yang ada dalam Islamicity performance index yaitu profit sharing ratio, zakat performance ratio, equitable distribution ratio, directors-employees welfare ratio, Islamic investment vs non-Islamic investment danlslamic income vs nonIslamic income.

Beberapa penelitian telah dilakukan untuk mengukur kinerja fungsi sosial bank syariah dengan menggunakan rasio Islamicity performance. Sebtianita (2015) dalam jurnalnya "Analisis Kinerja Bank Umum Syariah dengan Menggunakan Pendekatan Islamicity Performance Index dengan studi kasus pada bank umum syariah periode 20092013" menyatakan bahwa secara keseluruhan pendekatan Islamicity performance index sudah diterapkan pada kinerja Bank Umum Syariah tahun 2009-2013. Selain itu, Falikhatun dkk (2012) dalam jurnalnya "Bank Syariah di Indonesia: Ketaatan pada Prinsip-prinsip Syariah dan Kesehatan Finansial" 
Lutfiandari, et al/Jurnal Ekonomi Syariah Teori dan Terapan Vol. 3 No. 6 Juni 2016: 430-443; ANALISIS TREN DAN PERBANDINGAN RASIO ISLAMICITY PERFORMANCE PADA BANK SYARIAH MANDIRI, BANK MUAMALAT INDONESIA, BANK BRI SYARIAH DAN BANK BNI SYARIAH PERIODE 2011-2014

menyatakan bahwa IIR, PSR, ISIR, dan DEWR berpengaruh positif signifikan terhadap kesehatan finansial perbankan syariah.

Berdasarkan uraian yang telah dijelaskan, maka peneliti dapat merumuskan masalah penelitian bagaimana tren rasiolslamicity performance pada Bank Syariah Mandiri, Bank Muamalat Indonesia, Bank BRI Syariah dan Bank BNI Syariah periode 2011-2014 dan apakah terdapat perbedaan rasio Islamicity performance pada Bank Syariah Mandiri, Bank Muamalat Indonesia, Bank BRI Syariah dan Bank BNI Syariah periode 2011-2014.

Adapun tujuan penelitian ini adalah untuk mengetahui tren rasiolslamicity performance pada Bank Syariah Mandiri, Bank Muamalat Indonesia, Bank BRI Syariah dan Bank BNI Syariah periode 2011-2014 dan mengetahui perbedaan rasio Islamicity performance pada Bank Syariah Mandiri, Bank Muamalat Indonesia, Bank BRI Syariah dan Bank BNI Syariah periode 2011-2014.

\section{LANDASAN \\ TEORI \\ PENGEMBANGAN HIPOTESIS}

DAN

Bank syariah adalah bank yang beroperasi sesuai prinsip-prinsip syariah Islam, yakni bank yang operasionalnya mengikuti ketentuan syariah khususnya menyangkut tata cara muamalah secara Islam (Karmaen dan Antonio, 1997:1).

Analisis Subramanyan dan Wild (2010:4) menyatakan bahwa analisis laporan keuangan (Financial statement analysis) adalah aplikasi dari alat dan teknik analisis laporan kevangan bertujuan umum dan data-data yang berkaitan untuk menghasilkan estimasi dan kesimpulan yang bermanfaat dalam analisis bisnis.

Analisis laporan keuangan dilakukan agar laporan keuangan dapat dipahami dan juga dimengerti oleh berbagai pihak dengan tujuan utama yaitu agar dapat mengetahui posisi keuangan perusahaan saat itu, sehingga akan terlihat apakah suatu perusahaan tersebut telah mencapai target atau belum agar pemilik dan manajemen dapat merencanakan serta mengambil keputusan untuk kedepannya (Kasmir, 2013: 66-67).

Analisis tren merupakan salah satu teknik dari analisis laporan keuangan komparatif (comparative financial statement analysis) yang menjadi salah satu dari lima jenis alat yang dipergunakan untuk melakukan analisis keuangan. Keunggulan dari analisis ini adalah penyajian dalam angka absolut maupun presentase yang menjadi relevan karena dasar mata uang yang berbeda sehingga dapat menghasilkan perubahan besar yang tidak konsisten dengan kepentingan aktualnya (Subramanyan dan Wild, 2010:35).

Kasmir (2013:84) menyebutkan bahwa rumus untuk mencari angka indeks adalah sebagai berikut :

Angka indeks $=\frac{\text { tahun pembanding }}{\text { tahun dasar }} \times 100 \%$.....(2.1) 
Lutfiandari, et al/Jurnal Ekonomi Syariah Teori dan Terapan Vol. 3 No. 6 Juni 2016: 430-443; ANALISIS TREN DAN PERBANDINGAN RASIO ISLAMICITY PERFORMANCE PADA BANK SYARIAH MANDIRI, BANK MUAMALAT INDONESIA, BANK BRI SYARIAH DAN BANK BNI SYARIAH PERIODE 2011-2014

Hameed et al (2004) melalui jurnalnya telah mengembangkan sebuah indeks yang dinamakan Islamicity Performance Index, yang terdiri dari :

\section{Profit Sharing Ratio (PSR)}

PSRmerupakan salah satu rasio untuk mengukur aktivitas bank syariah dalam melakukan penyaluran pembiayaan yang berakad bagi hasil. Persamaan yang digunakan:

$$
\text { PSR }=\frac{\text { Mudharabah }+ \text { Musyarakah }}{\text { Total Pembiayaan }} .
$$

\section{Zakat Performance Ratio (ZPR)}

ZPR merupakan rasio yang mengukur seberapa besar zakat yang dikeluarkan oleh bank syariah dibandingkan dengan net asset. Persamaan yang digunakan:

$$
\text { ZPR }=\frac{\text { Zakat }}{\text { Net Asset }} .
$$

3. Equitable Distribution Ratio

$$
\text { Rasio ini pada dasarnya }
$$
mencoba untuk mencari tahu bagaimana pendapatan yang dihasilkan oleh bankbank syariah telah didistribusikan di antara pemangku kepentingan yang diwakili oleh jumlah yang dibelanjakan untuk qardh dan sumbangan, biaya karyawan dan lain-lain.

Persamaan yang digunakan adalah jumlah dana bantuan, beban tenaga kerja, shareholder, laba bersih dibagi dengan pendapatan setelah dikurangi zakat dan pajak.

$$
\frac{\text { dana bantuan }+ \text { beban tenaga kerja }+ \text { laba bersih }}{\text { pendapatan }-(\text { zakat }+ \text { pajak })}
$$

\section{Directors-Employees Welfare Ratio (DEWR)}

DEWR bertujuan untuk mengidentifikasi berapa uang yang digunakan untuk gaji direktur dibandingkan dengan vang yang digunakan untuk kesejahteraan pegawai. Kesejahteraan karyawan meliputi gaji, pelatihan, dll. Persamaan yang digunakan:

DEWR = rata-rata gaji direktur : rata-rata kesejahteraan karyawan....(2.5)

5. Islamic Investment Vs Non Islamic Investment (IIR)

Rasio yang membandingkan antara investasi halal dengan total investasi yang dilakukan bank secara keseluruhan. Persamaan yang digunakan:

$\| R=\frac{\text { investasi halal }}{\text { investasi halal+investasi non halal }} \ldots \ldots \ldots(2.6)$

6. Islamic Income Vs Non Islamic Income (ISIR)

IsIR merupakan rasio yang membandingkan antara pendapatan halal dengan seluruh pendapatan yang diperoleh bank syariah secara keseluruhan. Persamaan yang digunakan: $|S| R=\frac{\text { pendapatan halal }}{\text { pendapatan halal }+ \text { pendapatan non halal }} \ldots . .$.

\section{AAOIFIIndex}

Indeks ini adalah indeks yang digunakan untuk mengukur seberapa jauh lembaga syariah telah memenuhi prinsipprinsip syariah yang ditetapkan dalam Accounting and Auditing Organization for Islamic Financial Institutions (AAOIFI). reholder Datam penelitian ini AAOIFI index tidak digunakan karena indeks tersebut tidak tercantum dalam laporan keuangan bank umum syariah di Indonesia. 
Lutfiandari, et al/Jurnal Ekonomi Syariah Teori dan Terapan Vol. 3 No. 6 Juni 2016: 430-443; ANALISIS TREN DAN PERBANDINGAN RASIO ISLAMICITY PERFORMANCE PADA BANK SYARIAH MANDIRI, BANK MUAMALAT INDONESIA, BANK BRI SYARIAH DAN BANK BNI SYARIAH PERIODE 2011-2014

Model Analisis dalam penelitian ini dapat digambarkan sebagai berikut:

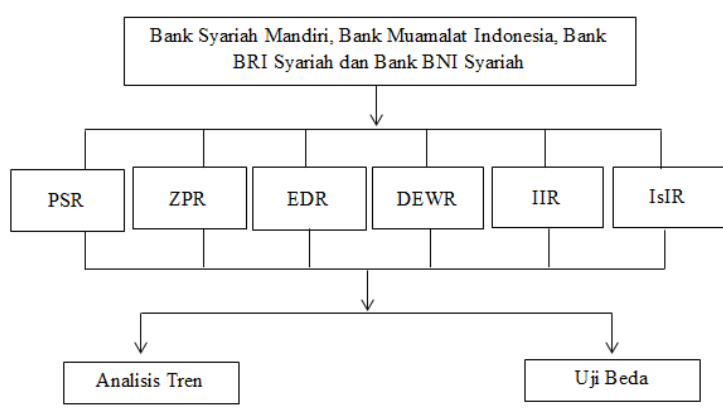

Sumber: Penulis

\section{Gambar 1. Model Analisis}

Hipotesis pada penelitian ini adalah terdapat perbedaan PSR, ZPR, EDR, DEWR, IIR, dan IsIR pada Bank Syariah Mandiri, Bank Muamalat Indonesia, Bank BRI Syariah dan Bank BNI Syariah

\section{METODE PENELITIAN}

Pendekatan yang digunakan dalam penelitian ini adalah pendekatan kuantitatif. Pendekatan kuantitatif merupakan penelitian terstruktur dan mengkuantifikasikan data untuk dapat digeneralisasi (Anshori dan Iswati, 2009:13).

Variabel dalam penelitian ini adalah profit sharing ratio, zakat performance ratio, equitable distribution ratio, directors-employees welfare ratio, Islamic investment vs non Islamic investment, Islamic income vs non Islamic income.

Adapun definisi operasional dalam penelitian ini adalah :

1. Profit Sharing Ratio (PSR)

PSR diperoleh dari besarnya danamudharabah ditambah musyarakah dibagi total pembiayaan. PSR didapat dari persamaan 2.2. Skala pengukuran dalam nilai PSR menggunakan skala rasio.

2. Zakat Performance Ratio (ZPR)

ZPRmerupakan rasio yang digunakan untuk mengukur besar zakat yang dikeluarkan bank jika dibandingkan dengan net asset. Net asset adalah kekayaan bersih (total aktiva dikurangi total kewajiban). Zakat performance ratio didapat dari persamaan 2.3. Skala pengukuran dalam nilai ZPR menggunakan skala rasio.

3. Equitable Distribution Ratio (EDR)

EDR digunakan untuk mencari rasio distribusi di antara semua pihak (karyawan, nasabah, perusahaan, masyarakat) guna menilai pemerataan bagi hasil dari berbagai pihak di perusahaan perbankan syariah. EDR didapat dari persamaan 2.4. Skala pengukuran dalam nilai EDR menggunakan skala rasio.

4. Directors-Employees Welfare Ratio (DEWR)

DEWR merupakan rasio yang membandingkan antara gaji direktur berbanding dengan vang yang digunakan untuk kesejahteraan pegawai. Kesejahteraan karyawan meliputi gaji, pelatihan, dll. DEWR didapat dari persamaan 2.5. Skala pengukuran dalam nilai DEWR menggunakan skala rasio.

5. Islamic Invesmtment vs Non Islamic Investment (IIR)

IIR merupakan rasio yang membandingkan antara investasi halal dengan total investasi yang dilakukan 
Lutfiandari, et al/Jurnal Ekonomi Syariah Teori dan Terapan Vol. 3 No. 6 Juni 2016: 430-443; ANALISIS TREN DAN PERBANDINGAN RASIO ISLAMICITY PERFORMANCE PADA BANK SYARIAH MANDIRI, BANK MUAMALAT INDONESIA, BANK BRI SYARIAH DAN BANK BNI SYARIAH PERIODE 2011-2014

oleh bank syariah secara keseluruhan (halal dengan non halal). IIR didapat dari persamaan 2.6. Skala pengukuran dalam nilai IIR menggunakan skala rasio.

6. Islamic Income vs Non Islamic Income $(I S \mid R)$

IsIR pendapat dibagi dalam pendapatan halal dan pendapatan non halal, pembagian pendapatan juga dilakukan agar bank syariah bisa memastikan hanya menerima pendapatan dari sumber halal. ISIR didapat dari persamaan 2.7. Skala pengukuran dalam nilai ISIR menggunakan skala rasio.

Dalam penelitian ini, keseluruhan datanya adalah data sekunder yang dapat diperoleh dari laporan keuangan tahunan masing-masing bank mulai tahun 2011-2014 yang terdapat pada website resmi bank syariah dan laporan publikasi bank umum syariah dalam website resmi Bank Indonesia. Data yang digunakan berupa data panel karena dilakukan dengan melibatkan banyak sampel pada tiap periodenya (cross section) dan melibatkan urutan waktu (time series).

Populasi dalam penelitian ini adalah seluruh bank syariah yang ada di Indonesia. Teknik penentuan sampel yang digunakan dalam penelitian ini adalah teknik sampling purposive. Teknik purposive adalah teknik penentuan sampel dengan pertimbangan tertentu (Anshori dan Iswati, 2009:105).

Adapun pertimbangan dalam penelitian ini adalah bank umum syariah yang mempublikasikan laporan kevangan tahunan periode 2011-2014 dan memiliki kelengkapan data sesuai dengan yang dibutuhkan. Berdasarkan dengan kriteria diatas, maka dapat diambil 4 Bank Umum Syariah yang memenuhi semua kriteria tersebut yaitu Bank Syariah Mandiri, Bank Muamalat Indonesia, Bank BRI Syariah dan Bank BNI Syariah.

Langkah-langkah yang dipergunakan untuk menganalisis masalah yang telah dirumuskan adalah (1) Menghitung rasio Islamicity performance dengan menggunakan persamaan yang telah ditentukan, (2) melakukan analisis deskriptif untuk mengetahui nilai rata-rata (mean), nilai terbesar (maximum), dan nilai terendah (minimum) dari empat bank umum syariah tersebut selama empat tahun, (3) dari perhitungan rasio tersebut dilakukan analisis tren menggunakan persamaan 2.1, kemudian dilanjutkan dengan penggambaran tren dari empat bank syariah pada periode 2011-2014.

1. Uji normalitas

2. Uji beda dengan Uji F (ANOVA)

\section{Hasil dan Pembahasan}

1. Profit Sharing Ratio

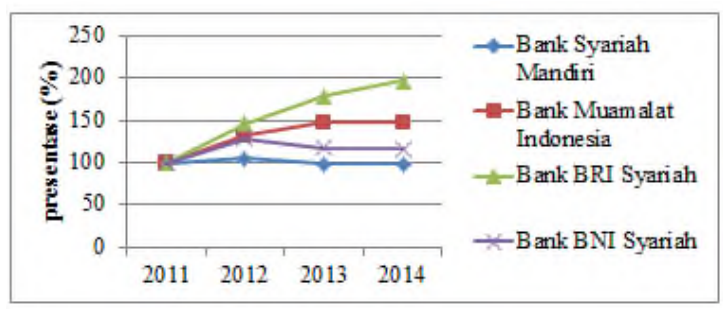

Sumber : data diolah

Grafik 1

Analisis Tren PSR 
Lutfiandari, et al/Jurnal Ekonomi Syariah Teori dan Terapan Vol. 3 No. 6 Juni 2016: 430-443; ANALISIS TREN DAN PERBANDINGAN RASIO ISLAMICITY PERFORMANCE PADA BANK SYARIAH MANDIRI, BANK MUAMALAT INDONESIA, BANK BRI SYARIAH DAN BANK BNI SYARIAH PERIODE 2011-2014

Pada grafik 1 dapat diketahui bahwa perkembangan PSR yang dimiliki oleh Bank BRI Syariah memiliki perkembangan tingkat PSR paling baik dibandingkan ketiga bank lainnya. Sedangkan Bank Syariah Mandiri mengalami perkembangan di titik paling bawah diantara bank lainnya.

\section{Zakat Performance Ratio}

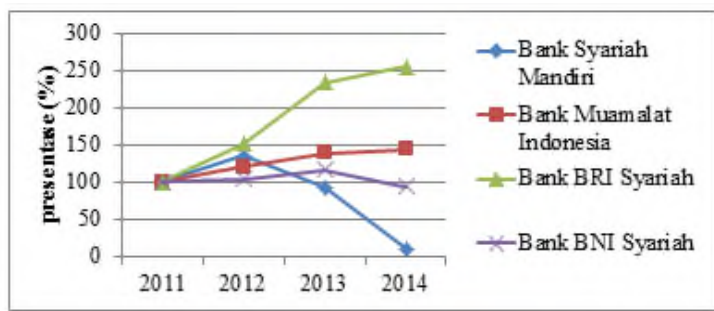

Sumber : data diolah

Grafik 2

\section{Analisis Tren ZPR}

Grafik di atas diketahui bahwa perkembangan ZPRdari Bank BRI Syariah meningkat dengan cukup baik. Bank BRI Syariah mengalami kenaikan mencapai titik tertinggi pada tahun 2014 yaitu 256\% sedangkan Bank Syariah Mandiri mengalami penurunan hingga titik terendah pada tahun 2014 yaitu 10,43\%.

3. Equitable Distribution Ratio

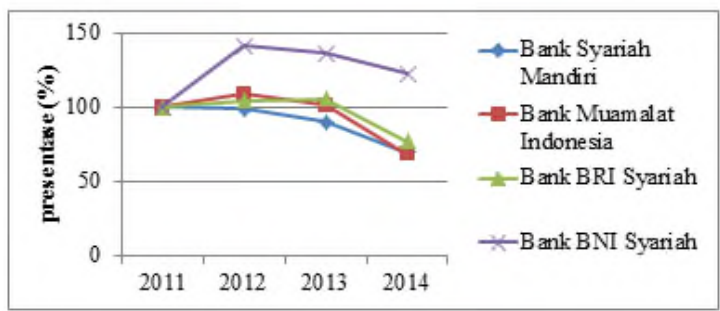

Sumber : data diolah

Grafik 3

Analisis Tren EDR

Berdasarkan grafik menggambarkan perkembangan tingkat EDR dari keempat bank tersebut mengalami perkembangan yang sama. Keempat bank tersebut mengalami penurunan pada tahun 20132014. Bank Muamalat Indonesia mengalami penurunan terendah dibandingkan ketiga bank lainnya yaitu pada titik $68,05 \%$

4. Directors-Employees Welfare Ratio

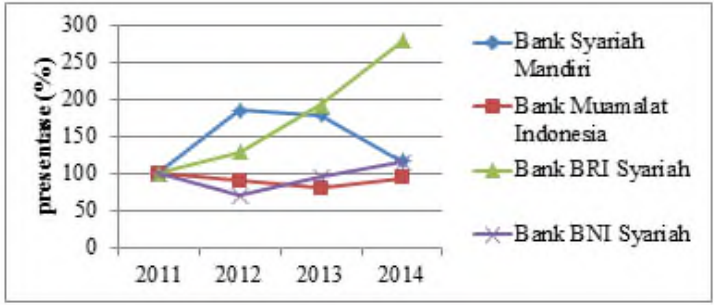

Sumber :data diolah

\section{Grafik 4}

Analisis Tren DEWR

Berdasarkan sajian grafik diatas, maka dapat dilihatpergerakan tren DEWR dari bank umum syariah sepanjang tahun 2011 hingga 2014. Diketahui bahwa bank BRI Syariah memilikipergerakan tren DEWR yang terus meningkat setiap tahunnya. Hal yang sama juga terjadi pada BNI Syariah dan Bank Muamalat. Namun, pada Bank Syariah Mandiri menujukkan adanya pergerakan tren yang menurun.

5. Islamic Investment vs Non Islamic Invesment

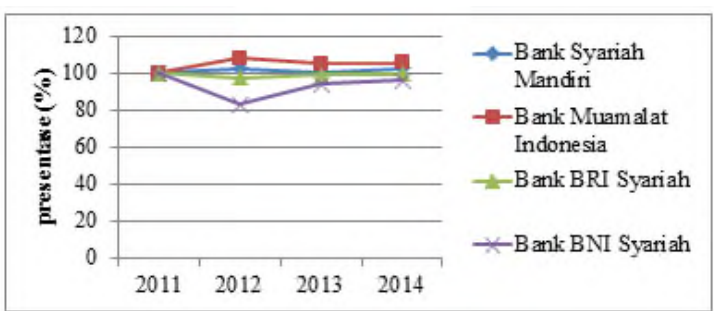

Sumber : data diolah

\section{Grafik 5}

Analisis Tren IIR

Secara keseluruhan Bank Syariah Mandiri, Bank Muamalat Indonesia, Bank BRI Syariah dan Bank BNI Syariah memiliki 
Lutfiandari, et al/Jurnal Ekonomi Syariah Teori dan Terapan Vol. 3 No. 6 Juni 2016: 430-443; ANALISIS TREN DAN PERBANDINGAN RASIO ISLAMICITY PERFORMANCE PADA BANK SYARIAH MANDIRI, BANK MUAMALAT INDONESIA, BANK BRI SYARIAH DAN BANK BNI SYARIAH PERIODE 2011-2014

perkembangan IsIR yang hampir sama. Presentase perbedaan diantara keempat bank tersebut hanya sedikit.

6. Islamic Income vs Non Islamic Income

Berdasarkan sajian grafik diketahui bahwa Bank BRI Syariah dan Bank BNI Syariah memiliki perkembangan IsIR yang hampir sama. Namun perkembangan IsIR Bank Syariah Mandiri yang mengalami penurunan yang signifikan pada tahun 2013 dan 2014.

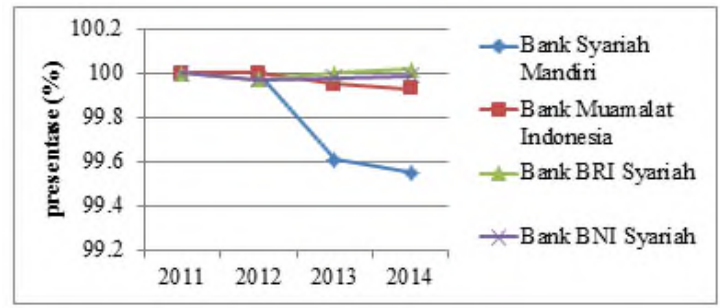

Sumber : data diolah

\section{Grafik 6 Analisis Tren IsIR}

Uji normalitas dilakukan bertujuan untuk memastikan apakah data telah memenuhi asumsi berdistribusi normal untuk dilakukan uji beda. Prosedur pengujian normalitas dilakukan dengan uji Shapiro-Wilk (Santoso, 2013:190). Adapun taraf signifikansi sebesar 0,05 . Jika nilai signifikansi hasil uji $\geq 0,05$ maka data berdistribusi normal dan dilakukan uji ANOVA namun, jika nilai signifikansi hasil uji $\leq 0,05$ maka data tidak berdistribusi normal maka menggunakan uji Kruskal-Wallis.
Tabel 1

Hasil Uji Normalitas

\begin{tabular}{|c|c|c|r|r|l|}
\hline Variabel & Bank & Df & Statistics & \multicolumn{1}{|c|}{ Sig. } & \multicolumn{1}{|c|}{ Keterangan } \\
\hline \multirow{4}{*}{ PSR } & BSM & 4 & 0.825 & 0.155 & Normal \\
\cline { 2 - 6 } & BMI & 4 & 0.822 & 0.148 & Normal \\
\cline { 2 - 6 } & BRIS & 4 & 0.959 & 0.774 & Normal \\
\cline { 2 - 6 } & BNIS & 4 & 0.947 & 0.698 & Normal \\
\hline \multirow{4}{*}{ ZPR } & BSM & 4 & 0.904 & 0.451 & Normal \\
\cline { 2 - 6 } & BMI & 4 & 0.927 & 0.576 & Normal \\
\cline { 2 - 6 } & BRIS & 4 & 0.927 & 0.575 & Normal \\
\cline { 2 - 6 } & BNIS & 4 & 0.971 & 0.847 & Normal \\
\hline \multirow{4}{*}{ EDR } & BSM & 4 & 0.835 & 0.181 & Normal \\
\cline { 2 - 6 } & BMI & 4 & 0.813 & 0.127 & Normal \\
\cline { 2 - 6 } & BRIS & 4 & 0.780 & 0.071 & Normal \\
\cline { 2 - 6 } & BNIS & 4 & 0.920 & 0.538 & Normal \\
\hline \multirow{4}{*}{ IIR } & BSM & 4 & 0.844 & 0.206 & Normal \\
\cline { 2 - 6 } & BMI & 4 & 0.977 & 0.887 & Normal \\
\cline { 2 - 6 } & BRIS & 4 & 0.947 & 0.695 & Normal \\
\cline { 2 - 6 } & BNIS & 4 & 0.963 & 0.796 & Normal \\
\hline & BSM & 4 & 0.752 & 0.041 & Tidak Normal \\
\cline { 2 - 6 } & BMI & 4 & 0.922 & 0.546 & Normal \\
\cline { 2 - 6 } & BRIS & 4 & 0.902 & 0.442 & Normal \\
\cline { 2 - 6 } IsIR & BNIS & 4 & 0.904 & 0.453 & Normal \\
\hline \multirow{5}{*}{} & BSM & 4 & 0.786 & 0.079 & Normal \\
\cline { 2 - 6 } & BMI & 4 & 0.827 & 0.161 & Normal \\
\cline { 2 - 6 } & BRIS & 4 & 0.959 & 0.773 & Normal \\
\cline { 2 - 6 } & BNIS & 4 & 0.968 & 0.831 & Normal \\
\hline
\end{tabular}

Sumber: Data diolah

Berdasarkan hasil uji normalitas diketahui bahwa rasio PSR, ZPR, EDR, DEWR, dan IsIR memiliki nilai signifikansi $\geq$ 0,05 sehingga variabel tersebut berdistribusi normal dan memenuhi asumsi pertama uji ANOVA. Pada rasio IIR memiliki nilai signifikansi $\leq 0,05$ sehingga variabel tersebut tidak berdistribusi normal. Uji beda untuk data yang tidak berditribusi normal adalah uji Kruskal-Wallis.

Hasil uji hipotesis dalam penelitian ini adalah sebagai berikut

1. Profit Sharing Ratio (PSR)

Tabel 2

Hasil Uji ANOVA variabel PSR

\begin{tabular}{|ll|r|r|r|r|c|}
\hline & \multicolumn{1}{|c|}{$\begin{array}{c}\text { Sum of } \\
\text { Squares }\end{array}$} & \multicolumn{1}{c|}{ df } & Mean Square & \multicolumn{1}{c|}{ F } & Sig. \\
\hline PSR & Between Groups & .192 & 3 & .064 & 23.179 & .000 \\
& Within Groups & .033 & 12 & .003 & & \\
\hline & Total & .225 & 15 & & & \\
\hline
\end{tabular}

Sumber : data diolah

Pada tabel diketahui nilai $F$ variabel PSR sebesar 23,179 dengan signifikansi 0,000 . Nilai signifikansi tersebut lebih kecil dari 0,05 maka dapat diartikan bahwa ada perbedaan signifikan PSR yang dimiliki oleh Bank Syariah Mandiri, Bank Muamalat 
Lutfiandari, et al/Jurnal Ekonomi Syariah Teori dan Terapan Vol. 3 No. 6 Juni 2016: 430-443; ANALISIS TREN DAN PERBANDINGAN RASIO ISLAMICITY PERFORMANCE PADA BANK SYARIAH MANDIRI, BANK MUAMALAT INDONESIA, BANK BRI SYARIAH DAN BANK BNI SYARIAH PERIODE 2011-2014

Indonesia, Bank BRI Syariah dan Bank BNI

Syariah selama periode 2011-2014.

2. Zakat Performance Ratio (ZPR)

Tabel 3

Hasil Uji ANOVA variabel ZPR

\begin{tabular}{|c|c|c|c|c|c|c|}
\hline & & $\begin{array}{l}\text { Sum of } \\
\text { Squares }\end{array}$ & df & Mean Square & $F$ & Sig. \\
\hline ZPR & $\begin{array}{l}\text { Between Groups } \\
\text { Within Groups }\end{array}$ & $\begin{array}{l}.000 \\
.000\end{array}$ & $\begin{array}{r}3 \\
12\end{array}$ & $\begin{array}{l}.000 \\
.000\end{array}$ & 1.563 & .249 \\
\hline
\end{tabular}

Sumber : data diolah

Berdasarkan tabel dapat

diketahui nilai F variabel ZPR sebesar 1,563 dengan signifikansi 0,249 . Nilai signifikansi tersebut lebih besar dari 0,05 maka dapat diartikan bahwa secara umum tidak terdapat perbedaan ZPR yang dimiliki oleh Bank Syariah Mandiri, Bank Muamalat Indonesia, Bank BRI Syariah dan Bank BNI Syariah selama periode 2011-2014.

3. Equitable Distribution Ratio (EDR)

Tabel 4

Hasil Uji ANOVA variabel EDR

\begin{tabular}{|ll|r|r|r|l|l|}
\hline & & \multicolumn{1}{|c|}{$\begin{array}{c}\text { Sum of } \\
\text { Squares }\end{array}$} & \multicolumn{1}{c|}{ df } & Mean Square & F & \multicolumn{1}{c|}{ sig. } \\
\hline EDR & Between Groups & .040 & 3 & .013 & 5.806 & .011 \\
& Whthin Groups & .027 & 12 & .002 & & \\
\hline & Total & .067 & 15 & & & \\
\hline
\end{tabular}

sumber : data diolah

Berdasarkan tabel 4.17 dapat diketahui nilai $F$ variabel EDR sebesar 5,806 dengan signifikansi 0,11 . Nilai signifikansi tersebut lebih kecil dari 0,05 maka dapat diartikan bahwa secara umum ada perbedaan signifikan EDR yang dimiliki oleh Bank Syariah Mandiri, Bank Muamalat Indonesia, Bank BRI Syariah dan Bank BNI Syariah selama periode 2011-2014.

4. Directors-Employees Welfare Ratio (DEWR)

Tabel 5

Hasil Uji ANOVA variabel DEWR

\begin{tabular}{|ll|r|r|r|r|c|}
\hline & \multicolumn{1}{|c|}{$\begin{array}{c}\text { Sum of } \\
\text { Squares }\end{array}$} & \multicolumn{1}{|c|}{ df } & Mean Square & F & Sig. \\
\hline DEWR & Between Groups & 2562.372 & 3 & 854.124 & 22.556 & .000 \\
& Within Groups & 454.406 & 12 & 37.867 & & \\
& Total & 3016.778 & 15 & & & \\
\hline
\end{tabular}

Sumber : data diolah
Berdasarkan tabel dapat diketahui nilai $F$ variabel DEWR sebesar 22,556 dengan signifikansi 0,000 . Nilai signifikansi tersebut lebih kecil dari 0,05 maka dapat diartikan bahwa secara umum ada perbedaan signifikan DEWR yang dimiliki oleh Bank Syariah Mandiri, Bank Muamalat Indonesia, Bank BRI Syariah dan Bank BNI Syariah selama periode 2011-2014.

5. Islamic Investment vs Non Islamic Investment (IIR)

Tabel 6 menunjukkan bahwa variabel IIR memiliki asymp.Sig $\geq 0,05$ maka dapat disimpulkan tidak terdapat perbedaan Islamicity performance index untuk variabel IIR yang dimiliki oleh Bank Syariah Mandiri, Bank Muamalat Indonesia, Bank BRI Syariah dan Bank BNI Syariah selama periode 2011-2014.

Tabel 6

Hasil Uji Kruskal-Wallis

\begin{tabular}{|l|r|}
\hline & \multicolumn{2}{|c|}{ IIR } \\
\hline Chi-Square & 6.618 \\
\hline Df & 3 \\
\hline Asymp.Sig. & .085 \\
\hline
\end{tabular}

Sumber : data diolah

6. Islamic Income vs Non Islamic Income

Tabel 7

Hasil Uji ANOVA

\begin{tabular}{|c|c|c|c|c|c|c|}
\hline & & $\begin{array}{l}\text { Sum of } \\
\text { Squares }\end{array}$ & df & Mean Square & $F$ & Sig. \\
\hline \multirow[t]{3}{*}{ ISIR } & Between Groups & .000 & 3 & .000 & \multirow[t]{3}{*}{2.762} & \multirow[t]{3}{*}{.088} \\
\hline & Within Groups & .000 & 12 & \multirow[t]{2}{*}{.000} & & \\
\hline & Total & .000 & 15 & & & \\
\hline
\end{tabular}

Sumber : data diolah

Berdasarkan tabel dapat diketahui nilai $F$ variabel IsIR sebesar 2,762 dengan signifikansi 0,088 . Nilai signifikansi tersebut lebih besar dari 0,05 maka dapat diartikan bahwa secara umum tidak ada 
Lutfiandari, et al/Jurnal Ekonomi Syariah Teori dan Terapan Vol. 3 No. 6 Juni 2016: 430-443; ANALISIS TREN DAN PERBANDINGAN RASIO ISLAMICITY PERFORMANCE PADA BANK SYARIAH MANDIRI, BANK MUAMALAT INDONESIA, BANK BRI SYARIAH DAN BANK BNI SYARIAH PERIODE 2011-2014

perbedaan Islamicity performance index untuk variabel IsIR yang dimiliki oleh Bank Syariah Mandiri, Bank Muamalat Indonesia, Bank BRI Syariah dan Bank BNI Syariah selama periode 2011-2014.

\section{Pembahasan}

\section{Profit Sharing Ratio (PSR)}

Perkembangan PSR yang dimiliki oleh keempat bank mengalami peningkatan meskipun masih dibawah $50 \%$. Hal ini disebabkan, bank syariah sebagai unit bisnis dalam rangka melaksanakan "amanat" pemilik dana berusaha mencarikan bidang usaha yang "profitable" dengan mempertimbangkan skala prioritas pada sektor yang menghasilkan keuntungan terbesar dengan risiko terkecil yaitu pada pembiayaan yang timbul dari transaksi jual beli

Hasi uji ANOVA yang dilakukan menunjukkan terdapat perbedaan pada rasio PSR.Penelitian ini sesuai dengan penelitian yang dilakukan oleh Fadli (2012) yang dan Miranata (2014) yang menunjukkan hasil yang sama bahwa terdapat perbedaan yang signifikan pada bank umum syariah dari segi rasio PSR.

Perbedaan signifikan rasio PSR yang dimiliki keempat bank tersebut disebabkan oleh tidak adanya aturan yang menyebutkan standar besarnya proporsi pembiayaan yang berakad bagi hasil pada bank syariah di Indonesia.

\section{Zakat Performance Ratio (ZPR)}

Perkembangan ZPR Bank Syariah Mandiri, Bank Muamalat Indonesia, Bank BRI
Syariah dan Bank BNI Syariah masih sangat rendah. Hal ini ditunjukkan dengan rasio ZPR yang memiliki rata-rata $0,032 \%$. Dapat disimpulkan bahwa bank syariah di Indonesia masih kurang memperhatikan pengeluaran zakat yang sudah menjadi kewajiban untuk dibagikan sesuai dengan ketentuan yang berlaku.

Berdasarkan hasil uji ANOVA menunjukkan bahwa tidak terdapat perbedaan pada ZPR.Penelitian ini sesuai dengan hasil penelitian Fadli (2012) yang menyebutkan tidak terdapat perbedaan signifikan Islamicity performance index dari segi ZPR.

Tidak adanya perbedaan yang signifikan pada rasio zakat performance ratio tentunya dikarenakan adanya ketentuan yang sudah mutlak nilainya atau nisab yaitu 2,5\%. Namun, ketika net asset dari Bank Umum Syariah semakin tinggi, tentunya zakat yang dibayarkan juga akan semain besar.

Al-Ba'ly (2006:35) menyatakan bahwa zakat diwajibkan pada jumlah nilai harta perdagangan yang telah mencapai nisab serta lewat masa haulnya, adalah $1 / 40$ atau $2,5 \%$ dari jumlah nilainya. Semua hasil keuntungan juga termasuk harta yang dihitung dalam nisab zakat, karena harta tersebut merupakan harta sejenis dengan modal yang dimiliki.

\section{Equitable Distribution Ratio (EDR)}

Secara

keseluruhan perkembangan equitable distribution ratio pada Bank Syariah Mandiri, Bank Muamalat Indonesia, Bank BRI Syariah dan 
Lutfiandari, et al/Jurnal Ekonomi Syariah Teori dan Terapan Vol. 3 No. 6 Juni 2016: 430-443; ANALISIS TREN DAN PERBANDINGAN RASIO ISLAMICITY PERFORMANCE PADA BANK SYARIAH MANDIRI, BANK MUAMALAT INDONESIA, BANK BRI SYARIAH DAN BANK BNI SYARIAH PERIODE 2011-2014

Bank BNI Syariah memiliki kecenderungan pergerakan yang menurun.

Hal ini menujukkan bahwa bank syariah masih kurang memperhatikan proporsi pendapatan yang diperoleh untuk dibagikan kepada stakeholder. Namun, pada data yang diperoleh dari laporan keuangan menyatakan bahwa pandapatan bank syariah sebagian besar masih dialokasikan untuk melakukan pengembangan usaha, kecukupan modal dan akuisisi bisnis baru.

Berdasarkan hasil uji ANOVA, menunjukkan bahwa terdapat perbedaan EDR dari keempat bank tersebut. Hasil penelitian ini sesuai dengan penelitian yang dilakukan oleh Miranata (2014) yang membuktikan terdapat perbedaan rasio EDR antara Bank Syariah Mandiri dengan Bank Mega Syariah selama tahun 2008-2012.

Perbedaan yang terdapat pada equitable distribution ratio dikarenakan setiap bank syariah memiliki prosentase pendapatan yang dibagikan kepada stakeholder berbeda. Hal ini dikarenakan bank memiliki ketentuan sendiri tentang besar kecilnya pembagian dana untuk stakeholdernya yang dimilikinya, seperti patokan beban gaji, dividen saham, laba bersih dan jumlah dana kebajikan dari masing-masing bank syariah.

\section{Directors-Employees Welfare Ratio (DEWR)}

Perkembangan bank umum syariah berdasarkan analisis tren DEWR masih berfluktuatif, sehingga dapat disimpulkan pembagian gaji direktur dan pegawai pada bank umum syariah masih belum merata sesuai dengan kewajiban yang dimilikinya untuk memperhatikan keadilan pada besarnya gaji direktur dan pegawai.

Hasil uji ANOVA menyatakan bahwa terdapat perbedaan pada DEWR yang ada di keempat bank syariah tersebut. Hasil ini mendukung temuan dalam penelitian yang dilakukan oleh Miranata (2014) yang menyatakan bahwa DEWR pada Bank Syariah Mandiri berbeda signifikan dengan Bank Mega Syariah.

Adanya perbedaan pada DEWR dapat dikarenakan standarisasi gaji pada masing-masing perusahaan yang berbeda. Meskipun berdasarkan peraturan pemerintah yang berlaku, sistem gaji sudah memiliki peraturan sendiri bagi perusahaan perseroan misalnya yaitu upah minimum regional (UMR), namun hal ini tetap berpeluang memiliki perbedaan disesuaikan dengan analisis jabatan dan evaluasi jabatannya.

\section{Islamic Investment vs Non Islamic Investment (IIR) \\ Hasil analisistren menunjukkan} perkembangan yang dimiliki keempat bank syariah tersebut sudah melebihi $90 \%$ untuk investasi halalnya maka dapat dikatakan bahwa kedua bank syariah ini sudah menunjukkan hasil kinerja yang memuaskan.

Berdasarkan hasil Hasil uji Kruskal Wallis yang dilakukan menunjukkan bahwa tidak ada perbedaan pada IIR pada keempat bank tersebut. Hasil penelitian ini mendukung penelitian Miranata (2014) yang menunjukkan 
Lutfiandari, et al/Jurnal Ekonomi Syariah Teori dan Terapan Vol. 3 No. 6 Juni 2016: 430-443; ANALISIS TREN DAN PERBANDINGAN RASIO ISLAMICITY PERFORMANCE PADA BANK SYARIAH MANDIRI, BANK MUAMALAT INDONESIA, BANK BRI SYARIAH DAN BANK BNI SYARIAH PERIODE 2011-2014

bahwa tidak terdapat perbedaan pada bank umum syariah dari segi rasio IIR.

Cara penempatan dana untuk investasi pada bank syariah diwajibkan pada sektor yang halal yaitu, dengan mempertimbangkan sumber dana yang diperolehnya dari investasi yang berakad wadiah dan mudharabah-mutlaqah serta sumber dana yang berakad mudharabah-muqayyadah ataupun sebagai pelaksanaan program pemerintah (Muhammad, 2004:221).

Tidak berbedanya Islamic investment vs non Islamic investment tersebut berdasarkan penempatan investasi pada bank umum syariah sudah ditentukan pada entitas syariah di Indonesia seperti fasilitas simpanan Bank Indonesia syariah, sertifikat Bank Indonesia syariah, surat berharga syariah negara, dll oleh Bank Indonesia.

\section{Islamic Income vs Non Islamic Income (IsIR)}

Hasil uji Anova yang dilakukan menunjukkan bahwa tidak terdapat perbedaan dari IsIRkeempat bank tersebut. Hasil penelitian ini mendukung penelitian Miranata (2014) yang menunjukkan bahwa terdapat perbedaan yang signifikan pada bank umum syariah dari segi rasio IsIR.

\section{Berdasarkan laporan keuangan} dan analisis tren yang dilakukan menunjukkan proporsi investasi halal pada keempat bank syariah hampir sama yaitu diatas $90 \%$ yang daoat diartikan bahwa keempat bank tersebut cukup berhasil dalam melaksanakan prinsip dasar dari bank syariah yaitu terbebas dari unsur riba.

Menurut Arifin (2009:67) sumber pendapatan bank syariah terdiri dari: bagi hasil atas kontrak mudharabah dan musyarakah; keuntungan atas kontrak jual beli; hasil sewa atas kontrak ijarah dan fee atas biaya administrasi dan jasa-jasa lainnya.Tidak adanya perbedaan pada ISIR sesuai dengan di atas, yaitu karena pendapatan bank umum syariah ditentukan pada sumber pendapatan sesuai akad-akad tersebut. Selain itu, berdasarkan hasil analisis tren menunjukkan bahwa rata-rata pendapatan halal keempat bank tersebut hampir sama.

\section{v. SIMPULAN}

1. Berdasarkan analisis tren perkembangan pada rasio PSR, ZPR, EDR dan ISIR yang dimiliki oleh Bank BRI Syariah paling baik jika dibandingkan bank lainnya namun pada perkembangan rasio DEWR Bank BRI Syariah tidak lebih baik dari bank lainnya, sedangkan Bank Muamalat Indonesia memiliki perkembangan rasio IIR yang lebih baik jika dibandingkan dengan bank lainnya.

2. Berdasarkan uji beda Bank Syariah Mandiri, Bank Muamalat Indonesia, Bank BNI Syariah dan Bank BRI Syariah dinyatakan bahwa terdapat perbedaan signifikan rasio PSR, EDR dan DEWR, sedangkan rasio ZPR, IIR dan ISIR tidak terdapat perbedaan yang signifikan. 
Lutfiandari, et al/Jurnal Ekonomi Syariah Teori dan Terapan Vol. 3 No. 6 Juni 2016: 430-443; ANALISIS TREN DAN PERBANDINGAN RASIO ISLAMICITY PERFORMANCE PADA BANK SYARIAH MANDIRI, BANK MUAMALAT INDONESIA, BANK BRI SYARIAH DAN BANK BNI SYARIAH PERIODE 2011-2014

DAFTAR PUSTAKA

Al-Ba'ly, Abdul Al-Hamid Mahmud. 2006.

Ekonomi Zakat. Jakarta: PT

RajaGrafindo Persada

Anshori, Muslich dan Sri Iswati. 2009. Metodologi Penelitian Kuantitatif. Surabaya:Airlangga University Press

Arifin, Zainul. 2009. Dasar-dasar Manajemen Bank Syariah. Jakarta: Raja Grafindo Persada.

Bank BNI Syariah. Laporan Tahunan Publikasi. (online),

(http://bnisyariah.co.id, diakses 20 September 2015)

Bank BRI Syariah. Laporan Tahunan Publikasi. (online),

(http://brisyariah.co.id, diakses 20 September 2015)

Bank Indonesia. Surat Edaran Bank Indonesia. (online),

(http://www.bi.go.id, diakses 7 September 2015)

Bank Muamalat Indonesia. Laporan Tahunan Publikasi. (online), (http://bankmuamalat.co.id, diakses 20 September 2015)

Bank Syariah Mandiri. Laporan Tahunan Publikasi. (online), (http://syariahmandiri.co.id, diakses 20 September 2015)

Departemen Agama RI. 2004. Mushaf AlQur'an dan Terjemahannya Revisi Tahun 2004. Jakarta: DEPAG RI

Fadlli, M. Muhibbin. 2012. Analisis Perbandingan Kinerja Keuangan Bank Syariah Devisa dengan Bank Syariah Non Devisa dengan Menggunakan
Metode CAMEL dan Shariah Comformity Indicator Periode 20092010. Skripsi tidak diterbitkan. Surabaya Fakultas Ekonomi dan Bisnis Universitas Airlangga.

Falikhatun dan Assegaf.2012.Bank Syariah di Indonesia:Ketaatan Pada Prinsip Syariah dan Kesehatan Finansial.Jurnal Accounting and Management, (Online), (CBAM).Vol1No.1, (http://www.jurnal.unissula.ac.id,

diakses 20 Oktober 2015)

Hameed, Shahlul. 2004. Alternative Disclosure and Performance Measures for Islamic Banking, (Online), (www.iium.edu.my, diakses tanggal 29 September 2015)

Kasmir.2013.Analisis Laporam

Kevangan.Jakarta:Raja Grafindo Persada

Karnaen Perwaatmadja dan M. Syafi'i Antonio. 1997. Apa dan Bagaimana Bank Islam, Yogyakarta: PT. Dana Bakti Wakaf

Miranata, Rizky Akbar. 2014. Analisis Komparasi Kinerja Kevangan Bank Umum Syariah (BUS) Yang Ada di Indonesia Berdasarkan Islamicity Performance Index. Skripsi tidak diterbitkan. Fakultas Ekonomi Universitas Brawijaya Malang.

Muhammad, 2014. Manajemen Dana Bank Syariah. Jakarta:PT Raja Grafindo Persada

Republik Indonesia. 1998. Undang-Undang Nomor 10 Tahun 1998 Tentang Perubahan Atas UU No.7Tahun 1992 
Lutfiandari, et al/Jurnal Ekonomi Syariah Teori dan Terapan Vol. 3 No. 6 Juni 2016: 430-443; ANALISIS TREN DAN PERBANDINGAN RASIO ISLAMICITY PERFORMANCE PADA BANK SYARIAH MANDIRI, BANK MUAMALAT INDONESIA, BANK BRI SYARIAH DAN BANK BNI SYARIAH PERIODE 2011-2014

Tentang Perbankan. Jakarta: Republik Indonesia

$$
2008 . \quad \text { Undang- }
$$

UndangNomor 21 Tahun 2008 Tentang Perbankan Syariah. Jakarta: Republik Indonesia

Sebtianita,Evi.2015.Analisis Kinerja Bank Umum Syariah dengan Pendekatan Islamicity Performance Index.Jurnal Fakultas Ekonomi UIN Malang

Santoso, Singgih. 2013. Menguasai SPSS 21 di Era Informasi. Jakarta:PT Elex Media Komputindo.

Subramanyan, \& John J. Wild. 2010. Analisis Laporan Keuangan, buku 1. Jakarta: Salemba Empat 